\title{
A Novel Hybrid Approach to Estimate Customer Interruption Costs for Industry Sectors
}

\author{
Sinan Kufeoglu, Matti Lehtonen \\ Aalto University, Espoo, Finland \\ Email: sinan.kufeoglu@aalto.fi, matti.lehtonen@aalto.fi
}

Received June 18, 2013; revised July 18, 2013; accepted July 25, 2013

Copyright (C 2013 Sinan Kufeoglu, Matti Lehtonen. This is an open access article distributed under the Creative Commons Attribution License, which permits unrestricted use, distribution, and reproduction in any medium, provided the original work is properly cited.

\begin{abstract}
The power system infrastructure, operations and market have gone through radical changes for the last couple of decades. The society has become more dependent to the continuous electric power supply and hence the concept of electric power reliability has become more significant. At this point, understanding the economic outcomes of power outages is vital and imperative for both utilities and the customers. There are certain methodologies to understand the costs of power interruptions. This paper suggests a novel hybrid method that comprises of customer surveys and direct analytical methods to reach customer specific, objective and reliable results for the industry sector customers. The paper also brings a statistical approach to censor the zero and extreme responses given via the surveys.
\end{abstract}

Keywords: Customer Interruption Cost (CIC); Power Interruption; Customer Survey; Industry Sector

\section{Introduction}

Technological improvements bring more electrical equipments to our daily lives, which makes electricity a vital part of the daily routine. Whether the continuous electric supply is a social right or not is still debatable. However, the perception of the majority of the society is in the way that reaches electric power, which is a social right rather than considering electricity as a commodity. On the other hand, it is a fact that improved reliability is in favour of all members of the electric power market; the power generation companies, the utilities and the customers. However, since the customers are supposed to pay the costs of reliability improvements in the power network, the balance must be paid attention between these costs and the benefits of the higher reliability. At this point understanding the economic worth of the power interruptions becomes more crucial than it was in the past. Under the light of this fact, there have been numerous studies to come up with an estimation of the power outage costs over the past 30 years.

There are three major methodologies that are preferred and commonly used for customer outage costs assessment by the electric power society. These include indirect analytical methods, case studies and customer surveys [1]. The detailed information about these methods, the advantages and disadvantages of the approaches are presented in the publications [1,2].

The customer survey, among all, is the most preferred one that is being used in the analysis of the customer interruption costs (CIC) [3]. Since it is believed that a customer is the best one who can assess his/her economic losses due to power interruptions, the outcomes of this approach are regarded as the most accurate ones. The surveys are done via three different approaches, namely Direct Worth (DW) approach, Willingness to Accept (WTA) and Willingness to Pay (WTP) approaches [1]. However, there are certain concerns about this methodology. One of them is the difficulty of carrying out an extensive survey to reach solid conclusions about CICs. It takes too much time, effort and money to carry out a customer survey to evaluate the economic worth of power interruptions.

This paper introduces a new approach to estimate power interruption costs of industrial customers by making use of the results of a customer survey conducted in Finland. The recommended CIC characteristics of this study differ from the others by utilizing the analytical data and by presenting unique customer damage functions for each specific industrial subsector.

\section{The Material}

Indirect analytical method is an approach that contains 
objective data such as electricity prices or tariffs, value added or turnover of a related customer, gross national product of a country and the annual energy consumption of that country, region or customer [2].

Including publicly declared, easy to reach and most importantly objective data like electricity prices and turnovers makes this approach advantageous over the others. Furthermore, it is an easy, cheap and quite straightforward method to find out the outage costs without consuming too much time. On the other hand, however, the results of the analytical studies present too broad and average results while utilities seek for specific and customer based results. At this point, the customer survey method come forth as a better alternative for reaching customer specific results. Nonetheless, there are certain problems with the customer survey approach as well. Some respondents might give misleading answers intentionally to the questions in the questionnaire. These responses are called strategic responses [4] and they pose a serious danger to the final correctness of the customer survey studies.

The strategic responses are usually either too low or too high [5]. Some respondents might just express their losses as "zero" just to finish the questionnaire quickly, while some might exaggerate their losses by reporting extremely high monetary figures. These responses can be grouped in zero responses and extreme responses respectively. These undesired responses in the data sets bring the necessity of an elimination technique to censor the useless data points for carrying out healthy analysis and coming up credible suggestions for the estimation of the outage costs. The authors decided to use the z-score elimination method to detect and censor the outliers in the data set. A $\mathrm{z}$-score, or a standard score (the $\mathrm{z}$ value of the standard normal distribution), is the number of standard deviations an individual data point deviates from the mean. It is calculated as follows:

$$
z=(x-\mu) / \sigma
$$

where; $z$ is the $z$-score, $x$ is the value of the data point, $\mu$ is the mean of the data set and $\sigma$ is the standard deviation of the data set.

An extreme outlier is defined as an extreme point that is outside the range of typical data values in a data set. If the absolute value of the $z$-score of an element in the data set is equal or greater than 3.0, then that point is called an extreme outlier. By regarding the extreme outliers, the authors applied $z$-score test to the obtained data from the customer survey, in which the data set had been converted into natural logarithm values, and censored these outliers before going through further statistical analysis.

In this study the outcomes of a comprehensive customer survey designed to investigate the economic worth of power interruptions for the industrial sectors in
Finland has been used [6]. In the survey, the Direct Worth (DW) approach has been followed by asking the respondents their expected economic losses in case of different power interruption scenarios.

In the literature majority of the studies adopting customer surveys is done using the sector customer damage functions (SCDF), which include industrial, commercial, residential and agricultural sectors $[4,7,8]$. The authors believe that carrying out reliability worth analysis with the aid of SCDFs shall yield too broad results. The electrical equipments utilized in the manufacturing process or in the operations are different for each industrial sector customer. Thus it could be claimed that each industrial subsector has distinct and unique electric power consumption characteristics. To reach a better understanding for the outage cost characteristics and to get more precise results, instead of dividing the customers only into sectors, a more detailed approach has been chosen and followed. In the customer survey, the industry sector had been divided into subsectors as metal, food, chemical, glass, paper, timber, construction and electrical sectors. As a result, in this paper a new customer damage function (CDF), subsector customer damage function (SSCDF), has been defined and used. In the customer survey, the respondents were asked to evaluate their economic losses in case of different outage scenarios changing with interruption and customer characteristics. These characteristics contain duration and time of occurrence of the interruption, advance warning and type of customer. As a result two SSCDFs were defined as follows:

CICpp $=\frac{\text { Reported cost for an outage of } \mathrm{t} \text { hours }}{\text { Peak power of the customer }} \mathrm{in} € / \mathrm{kW}$

CICae

$=\frac{\text { Reported cost for an outage of thours }}{\text { Annual energy consumption of the customer }} \mathrm{in} € / \mathrm{kW}$

Before introducing the proposed methodology, the raw data of the reported outage cost for one hour of all Industry sectors have been illustrated as a histogram in Figure 1.

As it is seen in the histogram, the distribution of the responses is extremely right skewed. To cope with the skewness, and to carry out more credible analysis, converting the distribution into lognormal distribution has been suggested $[4,9]$. The log normal distribution of the acquired responses is given in Figure 2.

When the above histogram is analyzed, it can be seen that the distribution does not fit to lognormal distribution due to considerable amount of very low responses and some extreme responses. $z$-score test is then applied to censor the zero and extreme responses from the data set so that a better cost distribution that would fit to the log- 
normal one could be reached. The resulting histogram and lognormal histogram are presented in the Figures 3 and 4 respectively.

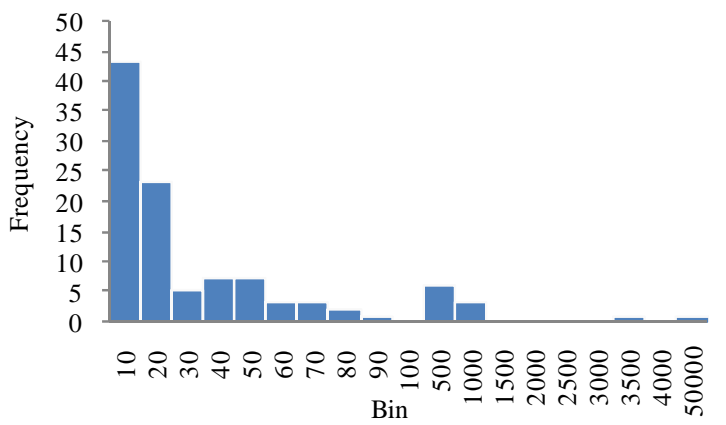

Figure 1. Uncensored distribution of the industry sector unexpected outage costs for 1 hour in $€ / \mathrm{kW}$.

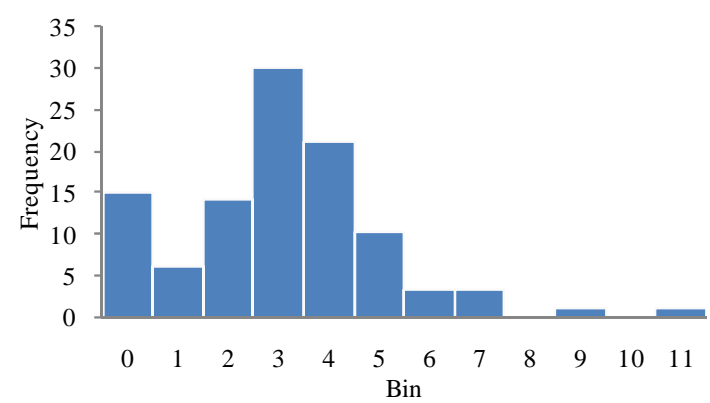

Figure 2. Uncensored lognormal distribution of the industry sector unexpected outage costs for 1 hour in $€ / \mathbf{k W}$.

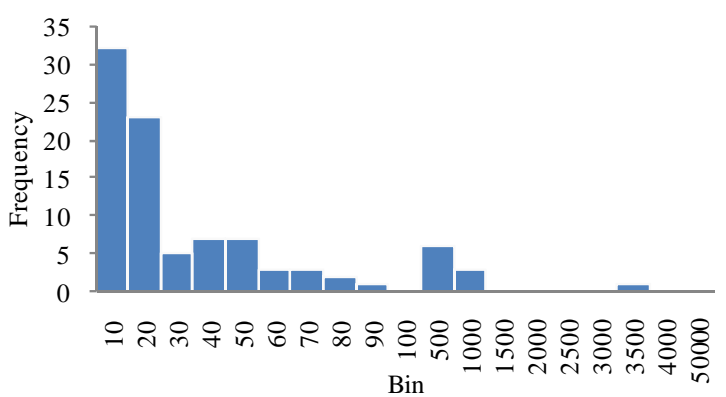

Figure 3. Censored distribution of the industry sector unexpected outage costs for 1 hour in $€ / \mathbf{k W}$.

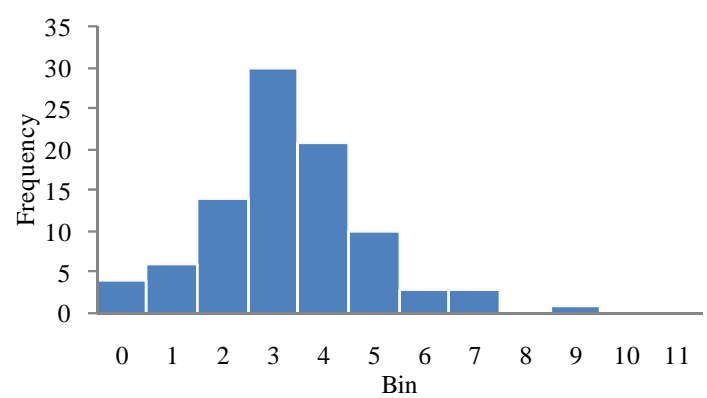

Figure 4. Censored lognormal distribution of the industry sector unexpected outage costs for 1 hour in $€ / \mathbf{k W}$.
The numerical values of the data set are first converted to natural $\log$ values. By applying $z$-score test, the extreme outliers were detected and the corresponding data points, which comprised of zero and extreme responses were eliminated. As a result, the remaining data set histogram fits lognormal distribution better than the raw data set histogram. By this way, reaching and interpreting typical values for the estimation of the CICs have become more reliable.

\section{Research Method}

The annual energy consumption and value added data of the industrial customers are objective and easy to reach information. By making use of these data, a CDF of CICva has been defined as the ratio of the value added for a certain time of period to the annual energy consumption corresponding to that time span. It is in $€ / \mathrm{kWh}$, and the load duration time for one year has been chosen to be $3000 \mathrm{~h}$ per year [10]. Since the value added per year $(€)$, the annual energy consumption $(\mathrm{kWh})$ and the load duration time (3000 h) are known for each subsector, CICva per hour can be calculated easily.

CICva forth our per $\mathrm{kWh}=\frac{\text { value added for one year }}{\text { annual energy } * 3000 \mathrm{~h}} * \mathrm{t}$

In an industrial facility, the continuous production is only available when there is continuous electric power. At this point it could be claimed that this production is linearly related to the value added that the facility creates. To illustrate the idea:

$$
\text { Production } \sim \text { Value added }
$$

In the customer survey, the respondents were asked to express their losses in percentages in the forms of production losses, restart losses, spoiled material losses, third party costs, damages and other costs for $1 \mathrm{~h}, 4 \mathrm{~h}$ and $8 \mathrm{~h}$ time spans. The results are summarized in Table 1.

\subsection{Unexpected Outages}

In case of an unexpected power interruption, the customer is caught unprepared and therefore, the facility suffers from all of the forms of costs expressed above. To make a bridge between the typical value of the CIC and the value added of each customer, a weighing factor $\mathbf{K u}$ has been defined as follows:

$$
\mathbf{K u}=\frac{100}{\text { percentage of production losses }}
$$

where;

Total losses $(100 \%)=$ production losses + restart losses + losses of spoiled materials + damages + third party costs + other costs

As a result a new and specific SSCDF for the unexpected outages has been defined as: 
Table 1. Average values of loss types in percentages for each industry sector.

\begin{tabular}{|c|c|c|c|c|c|c|}
\hline Sectors & Production & Restart & Spoiled Materials & Damages & Third Party Costs & Other \\
\hline Food & 50 & 3 & 36 & 1 & 0 & 10 \\
\hline Metal & 60 & 6 & 5 & 8 & 9 & 12 \\
\hline Paper & 58 & 15 & 2 & 4 & 0 & 21 \\
\hline Chemical & 43 & 25 & 6 & 0 & 0 & 26 \\
\hline Glass & 50 & 9 & 4 & 5 & 0 & 32 \\
\hline Timber & 67 & 12 & 2 & 3 & 12 & 4 \\
\hline Construction & 74 & 12 & 1 & 1 & 5 & 7 \\
\hline Electrical & 63 & 7 & 5 & 1 & 3 & 21 \\
\hline
\end{tabular}

$$
\mathrm{CICu}=\mathrm{Ku}^{*} \mathrm{CICva}
$$

\subsection{Planned Outages}

The characteristics of the outcomes of the planned outages differ from the unexpected ones. For the planned outage case, another weighing factor is needed to convert the value added information into CICae. If the facility is reported about a planned interruption before it occurs, the customer takes measures to minimize his/her losses. These measures comprise of preventing losses of spoiled materials, damages, third party costs and other costs. Therefore, as a result, the only losses that the industrial customer suffers will be mainly the production losses and restart losses. So, by following this logic, the second weighing factor for planned outages is defined:

$$
\mathbf{K p}=\frac{\text { perc. of production losses }+ \text { perc. of restart losses }}{\text { percentage of production losses }}
$$

As a result, similar to the one from the unexpected outages, another SSCDF for the planned outages has been defined as:

$$
\mathrm{CICp}=\mathrm{Kp} * \text { CICva }
$$

Since the power consumption characteristics and hence the interruption cost outcomes are distinct for each subsector, by the aid of the survey, the customer damage functions CICpp, CICae, CICva, CICu, CICp, and weighing factors $\mathrm{Ku}$ and $\mathrm{Kp}$ have been calculated for these sectors. The ultimate aim of this study is to present interruption cost estimations by reaching credible typical valuesfor each specific industrial sector. To achieve this goal, the censored typical value results of the SSCDFs have been compared and presented in the Results section.

\section{Results}

The typical values of $\mathrm{Ku}$ and $\mathrm{Kp}$ coefficients, the censored average values, for each sector have been calculated and tabulated on Tables 2 and 3.
Table 2. Typical values of Ku weighing factors for different industry sectors.

\begin{tabular}{ccccc}
\hline Sectors & $1 \mathrm{~h}$ & $4 \mathrm{~h}$ & $8 \mathrm{~h}$ & Average \\
\hline Food & 1.96 & 2.01 & 2 & 1.99 \\
Metal & 1.87 & 1.61 & 1.56 & 1.68 \\
Paper & 1.86 & 1.72 & 1.58 & 1.72 \\
Chemical & 3.48 & 2.17 & 1.88 & 2.51 \\
Glass & 2.37 & 1.91 & 1.79 & 2.03 \\
Timber & 1.71 & 1.52 & 1.32 & 1.52 \\
Construction & 1.43 & 1.31 & 1.31 & 1.35 \\
Electrical & 1.71 & 1.61 & 1.47 & 1.6 \\
\hline
\end{tabular}

Table 3. Typical values of Kp weighing factors for different industry sectors.

\begin{tabular}{ccccc}
\hline Sectors & $1 \mathrm{~h}$ & $4 \mathrm{~h}$ & $8 \mathrm{~h}$ & Average \\
\hline Food & 1.1 & 1.05 & 1.05 & 1.06 \\
Metal & 1.23 & 1.06 & 1.05 & 1.12 \\
Paper & 1.3 & 1.26 & 1.23 & 1.26 \\
Chemical & 1.96 & 1.44 & 1.53 & 1.64 \\
Glass & 1.45 & 1.11 & 1.07 & 1.21 \\
Timber & 1.3 & 1.18 & 1.08 & 1.19 \\
Construction & 1.16 & 1.15 & 1.15 & 1.16 \\
Electrical & 1.21 & 1.08 & 1.05 & 1.11 \\
\hline
\end{tabular}

To see the variation between each related SSCDF, the ratio of CICae vs. CICu and CICae vs. CICp have been plotted for each sector for varying time spans in Figures 5 and 6.

The results have shown that, as the outage time increases, the difference between the direct method and the econometric method, the Relative Worth approach, de- 
creases and the ratio approaches to unity. It can be claimed that, the proposed methodology can be adopted easily to calculate the interruption costs, especially, whenever the time span for the outage is longer than fifteen minutes where the variation is considerably large. The data for the 1 second interruption has been omitted here intentionally because the corresponding ratios were seen to be around thousands. We may conclude that our methodology fails to come up with credible estimation for momentary interruptions, which shall be investigated in a future study where the main subject will be the economic impacts of short outages and the voltage sags in the industry sectors.

The correlation between the direct costing SSCDF (CICae) and the econometric model SSCDFs (CICu, CICp) of each sector have been investigated to see the relation among these functions. To illustrate the point, by considering the volume concerns of the paper, only the results of the food sector have been plotted and presented in Figures 7 and 8.

The rest of the correlation coefficients for each sector have been tabulated and shown as a summary in Table 4 .

When the above graphs and the table are checked, except for the timber sector, it can be seen that there is almost perfect correlation between direct costing model and the proposed econometric models. This result is en-

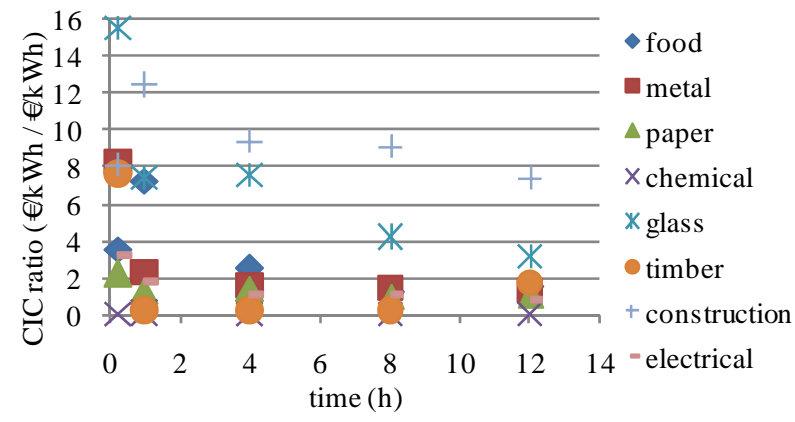

Figure 5. CICae/CICu ratios of industry sectors for the unexpected outage scenario.

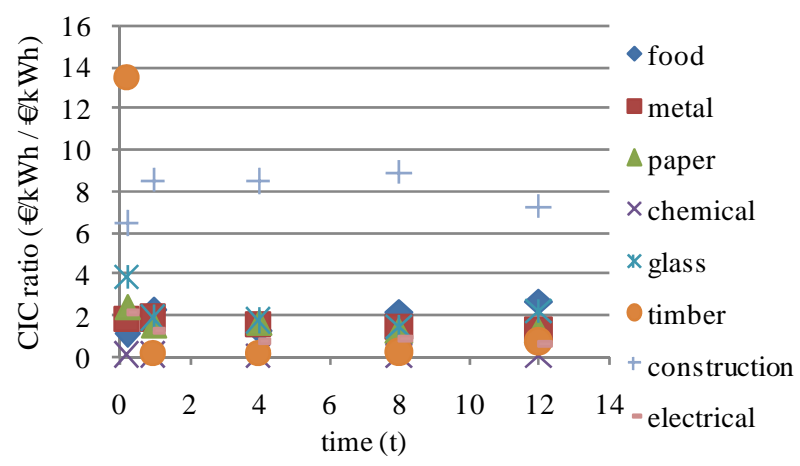

Figure 6. CICae/CICp ratios of industry sectors for the planned outage scenario.

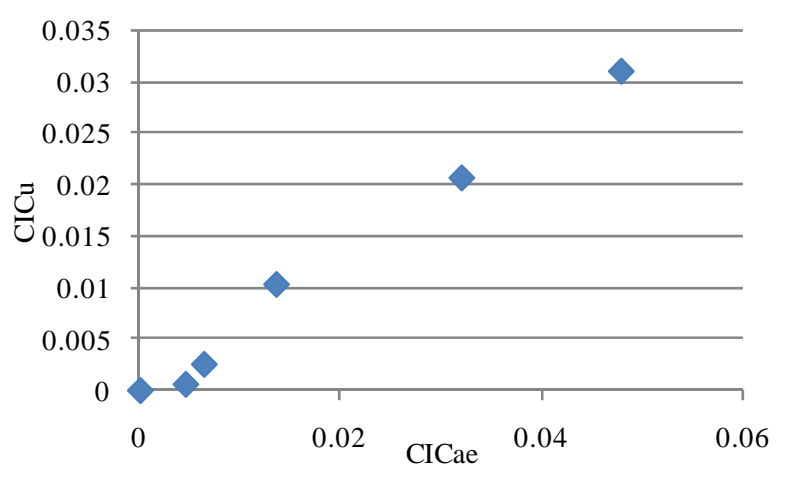

Figure 7. The correlation between CICae and CICu for the food sector for the unexpected outage scenario

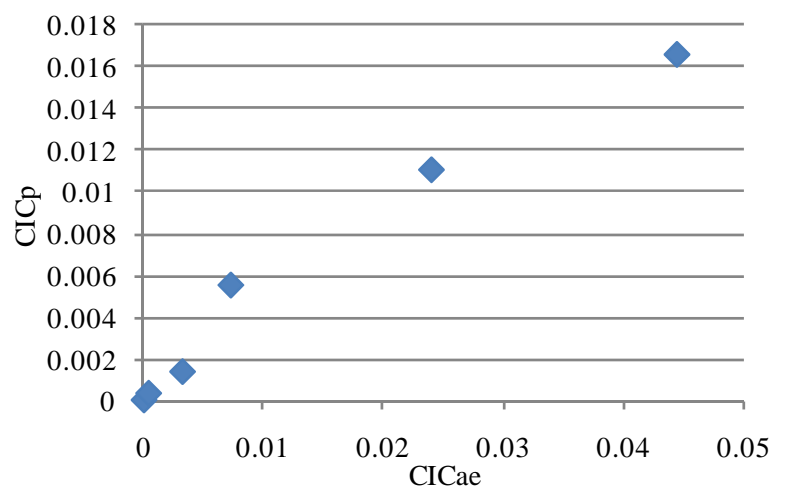

Figure 8. The correlation between CICae and CICp for the food sector for the planned outage scenario.

Table 4. The correlation coefficients for the industry sectors for both unexpected and planned outage scenarios respectively.

\begin{tabular}{ccc}
\hline Sectors & CICae-CICu & CICae-CICp \\
\hline Food & 0.99 & 0.98 \\
Metal & 0.99 & 0.99 \\
Paper & 0.99 & 0.99 \\
Chemical & 0.99 & 0.95 \\
Glass & 0.92 & 0.97 \\
Timber & 0.81 & 0.73 \\
Construction & 0.99 & 0.99 \\
Electrical & 0.98 & 0.99
\end{tabular}

couraging to reach a conclusion that the proposed econometric models are as credible as the direct costing one and they can be preferred as alternative tools of approaching the customer interruption cost estimation challenge in a faster, easier, cheaper and more objective way.

To observe the results of the customer survey in a different perspective, another subsector customer damage 
function, the reported monetary loss of a certain power outage for a certain time span divided by the peak power of the customer (CICpp), has been defined in The Material part of the paper. To avoid more analysis and by considering the volume of the paper, only the censored average values were calculated. The following typical values are tabulated in $€ / \mathrm{kW}$ for each industry sector in Tables 5 and 6.

\section{Summary and Conclusions}

In this paper, a new method was defined and proposed, by which the customers can easily assess their economic losses in case of an interruption by simply utilizing the corresponding outage cost estimation typical values to their area of business. In addition, both researchers and the utility professionals can make use of any typical value data sets, in $€ / \mathrm{kWh}$ and in $€ / \mathrm{kW}$, to go through a reliable regression analysis. By doing so, one can reach a quadratic formula unique for each subsector, which will eventually yield an estimation for the economic impacts of a possible outage for any time span. When compared to conventional customer survey studies, this methodol-

Table 5. Typical values of CICpp's for industry sectors in $€ / \mathbf{k W}$ of peak power for unexpected outage scenario.

\begin{tabular}{ccccccc}
\hline Sectors & $1 \mathrm{~s}$ & $15 \mathrm{~min}$ & $1 \mathrm{~h}$ & $4 \mathrm{~h}$ & $8 \mathrm{~h}$ & $12 \mathrm{~h}$ \\
\hline Food & 0 & 5.81 & 25.34 & 41 & 96.15 & 143.64 \\
Metal & 1.91 & 12.68 & 33.37 & 87.5 & 164.9 & 198.13 \\
Paper & 1.26 & 11.7 & 28.09 & 124.44 & 176.72 & 272.97 \\
Chemical & 0 & 3.62 & 20.85 & 41.01 & 92.42 & 118.18 \\
Glass & 3.91 & 27.65 & 48.94 & 197.16 & 221.74 & 251.47 \\
Timber & 1.49 & 6.67 & 15.4 & 67.87 & 131.75 & 165.17 \\
Construction & 0.08 & 15.85 & 53.84 & 145.92 & 284.12 & 346.48 \\
Electrical & 5.67 & 8.67 & 20.05 & 49.18 & 96.4 & 109.33 \\
\hline
\end{tabular}

Table 6. Typical values of CICpp's for industry sectors in $€ / \mathbf{k W}$ of peak power for planned outage scenario.

\begin{tabular}{ccccccc}
\hline Sectors & $1 \mathrm{~s}$ & $15 \mathrm{~min}$ & $1 \mathrm{~h}$ & $4 \mathrm{~h}$ & $8 \mathrm{~h}$ & $12 \mathrm{~h}$ \\
\hline Food & 0 & 5.23 & 9.64 & 21.7 & 71.81 & 133.16 \\
Metal & 0.19 & 5.15 & 18.33 & 56.05 & 95.34 & 123.78 \\
Paper & 0.32 & 9.34 & 24.4 & 102.04 & 160.97 & 246.39 \\
Chemical & 1.66 & 3.26 & 16.77 & 20.28 & 39.69 & 46.61 \\
Glass & 0.95 & 3.72 & 7.3 & 27.07 & 45.09 & 103.36 \\
Timber & 0.14 & 5.9 & 7.29 & 26.56 & 86.04 & 115.56 \\
Construction & 0.08 & 12.1 & 40.89 & 124.35 & 260.86 & 292.48 \\
Electrical & 1.14 & 3.93 & 9.07 & 22.76 & 49.57 & 61.99 \\
\hline
\end{tabular}

ogy provides an easy and straightforward way of coming up with more reliable figures for customer interruption costs by providing subsector specific results and eliminating strategic response issues to some degree.

The customer surveys are the most preferred way of handling the challenges of evaluating the economic impacts of the power interruptions. By experience, it is known that there is a big gap between the WTP and WTA values. This makes the direct worth (DW) approach the only credible tool that can be used in these surveys. However, DW approach is susceptible to biased answers resulting in subjective and unreliable conclusions. Thus a newer methodology, a Relative Worth (RW) approach seeking relative interruption costs compared to total loss will be easier to assess and will be more credible and objective by eliminating the strategic response problem. Therefore, the conventional customer surveys should be modified and redesigned in a way that the questionnaire shall be seeking the percentages of the different loss types instead of the monetary value of the different loss scenarios. $\mathrm{Ku}$ and $\mathrm{Kp}$ weighing factors could be more precise when there are more loss types in the questionnaire. On the other hand, if found necessary, new weighing factors can be defined and used in the future with new parameters in the calculation process.

Strategic response problem has been a challenge for the electric power society for the recent years. By using proper statistics tools, extreme and zero response problems might be eliminated. However, some responses to the questionnaire given intentionally to affect the results of the survey by some customers might still lie in the uncensored region of the data set. Getting rid of these responses, the strategic responses, seems impossible by the use of censoring methods. This makes the use of RW approach imperative, where the customer will not be asked to assess the losses in monetary terms but rather he/she will come up with relative loss figures. As a result, the problem of the exaggeration of the losses will be solved noticeably.

As it can be observed from the weighing factors, Tables 2 and 3, each industry sector has its own power consumption behaviours. For instance, the electric power consumption nature of construction and food sectors are significantly distinct, which eventually ends up with distinct CIC figures. That is why, analyzing all the sectors together, and presenting the results by averaging the data will yield too broad conclusions. That is why Sector Customer Damage Function (SCDF) approach fails to meet specific CICs for specific customer types. At this point the authors suggest the use of Subsector Customer Damage Function (SSCDF) to present unique assessment for each customer type.

Industrial sector is the easiest one among all to study CICs since there are eligible professionals at the customer 
side that can evaluate true losses due to power interruptions and can give more accurate answers to the survey questions. In addition, the strong correlation between continuous power and mass production makes it easier to form a link between CIC and value added figures. The direct costs are more significant than the indirect costs at the industry side, where investigating direct costs are simpler. Nevertheless, the picture changes dramatically for the other sectors. For the service sector, it is harder to interpret the relation between power supply and annual turnover, thus reaching a conclusion about a link between these two is more difficult. On the other hand, for the residential sector, the indirect costs could be claimed to be much higher due to the difficulty of assessing the economic worth of loss of leisure activities such as missing a football match for a customer who is a football fan. Although the power outage costs of residential customers are lower than those of the business customers $[11,12]$, a sound approach to estimate these costs is imperative as well. These observations clearly indicate that, in the future, more sophisticated and sector specific studies are necessary to evaluate the customer interruption costs in a more reliable way.

\section{REFERENCES}

[1] R. Billinton, "Methods to Consider Customer Interruption Costs: Task Force 38.06.01,” Cigré, Paris, 2001.

[2] G. Wacker and R. Billinton, "Customer Cost of Electric Service Interruptions,” Proceedings of the IEEE, Vol. 77, No. 6, 1989, pp. 919-930. http://dx.doi.org/10.1109/5.29332

[3] R. Billinton, et al., "Methods to Consider Customer Interruption Costs in Power Systems Analysis," CIGRE Task Force Report, Cigré, Paris, 2001.

[4] G. Kjølle, K. Samdal, B. Singh and O. Kvitastein, "Customer Costs Related to Interruptions and Voltage Prob- lems: Methodology and Results,” IEEE Transactions on Power Systems, Vol. 23, No. 3, 2008, pp. 1030-1038. http://dx.doi.org/10.1109/TPWRS.2008.922227

[5] K. Kivikko, A. Makinen,P. Jarventausta, A. Silvast, P. Heine and M. Lehtonen, "Comparison of Reliability Worth Analysis Methods: Data Analysis and Elimination Methods,” IET Generation, Transmission \& Distribution, Vol. 2, No. 3, 2008, pp. 321-329. http://dx.doi.org/10.1049/iet-gtd:20060532

[6] A. Silvast, P. Heine, M. Lehtonen, K. Kivikko, A. Mäkinen and P. Järventausta, "Customer Interruption Costs in Finland,” Teknillinen Korkeakoulu, Tampereen Teknillinen Yliopisto, Korkeakoulunkatu, 2005.

[7] R. Billinton, G. Tollefson and G. Wacker, "Assessment of Electric Service Reliability Worth,” Third International Conference on Probabilistic Methods Applied to Electric Power Systems, London, 3-5 July 1991, pp. 9-14.

[8] K. Samdal, G. H. Kjølle, B. Singh and O. Kvitastein, "Interruption Costs and Consumer Valuation of Reliability of Service in a Liberalized Power Market," 9th International Conference on Probabilistic Methods Applied to Power Systems, Stockholm, 11-15 June 2006, pp. 1-7.

[9] M. J. Sullivan, M. Mercuiro and J. Schellenberg, "Ernest Orlando Lawrence Berkeley National Laboratory,” 2009. http://certs.lbl.gov/pdf/lbnl-2132e.pdf

[10] M. Lehtonen, P. Heine, A. Silvast, K. Kivikko, A. Mäkinen and P. Järventausta, "Customers' Outage Costs in Electrical Distribution Networks," 5th International Conference Electric Power Quality and Supply Reliability, Viimsi, 23-26 August 2006, pp. 87-91.

[11] Public Service Company of Colorado, "2003 Least-Cost Resource Plan,” Volume 4 of 4, Technical Appendix, Public Service Company of Colorado, Denver, 2004.

[12] J. Eto, L. Lawton, M. Sullivan, K. Van Liere and A. Katz, "A Framework and Review of Customer Outage Costs: Integration and Analysis of Electric Utility Outage Cost Surveys,” Report No. LBNL-54365, Lawrence Berkley National Laboratory, Berkeley, 2003. 